\title{
In Vivo Antimammary Tumor Effects of Soybean Extract with Targeted Lunasin (ET-Lun)
}

\author{
Numlil Khaira Rusdi1 ${ }^{12}$, Erni Hernawati Purwaningsih ${ }^{3,7}$, Andon Hestiantoro ${ }^{4}$, Berna Elya ${ }^{5}$, Kusmardi Kusmardi ${ }^{6-8, *}$
}

\author{
Numlil Khaira Rusdi ${ }^{1,2}$, Erni \\ Hernawati Purwaningsih ${ }^{3,7}$, \\ Andon Hestiantoro ${ }^{4}$, Berna Elya ${ }^{5}$, \\ Kusmardi Kusmardi $6-8, *$
}

'Doctoral Program for Biomedical Sciences, Faculty of Medicine, Universitas Indonesia Jakarta, INDONESIA.

Jakarta, INDONESIA. 2Faculty of Pharmacy and Sciences, Universit Muhammadiyah Prof. DR. Hamka, Jakarta, INDONESIA.

${ }^{3}$ Department of Pharmacy, Faculty of Medicine, Universitas Indonesia, Jakarta, INDONESIA. ${ }^{4}$ Department Obstetrics and Gynaecology, School of Medicine, Universitas Indonesia, Dr Cipto Mangunkusumo Hospital, Jakarta, INDONESIA. ${ }^{5}$ Department of Phytochemistry, Faculty of 'Department of Phytochemistry, Faculty of Pharmacy,

${ }^{6}$ Department of Anatomic Pathology, Faculty of Medicine, Universitas Indonesia, Jakarta, INDONESIA.

${ }^{7}$ Drug Development Research Cluster, Indonesian Medical Education and Reseach Institute, Universitas INDONESIA.

${ }^{8}$ Human Cancer Research Cluster, Indonesian Medical Education and Research Institute, Universitas INDONESIA.

\section{Correspondence}

\section{Kusmardi Kusmardi}

Department of Anatomic Pathology,

Faculty of Medicine, Universitas Indonesia, Jakarta; Drug Development Research

Cluster; Human Cancer Research

Cluster, Indonesian Medical Education and Research Institute, Universitas INDONESIA.

E-mail: kusmardi.ms@ui.ac.id

History

- Submission Date: 17-06-2021;

- Review completed: 11-07-2021;

- Accepted Date: 20-07-2021.

DOI : 10.5530/pj.2021.13.160

Article Available online

http://www.phcogj.com/v13/i5

Copyright

(C) 2021 Phcogj.Com. This is an open access article distributed under the terms of the Creative Commons Attribution 4.0 International license.

\begin{abstract}
Background/Objective: Lunasin is a peptide, consist of 44 amino acids which have anti-cancer antioxidant, and anti-inflammatory activity. The price of commercial Lunasin was very expensive due to the high cost of lunasin synthesis and the lack of methods to obtain the pure lunasin weight from plant sources, involving time-consuming analytical instruments. To overcome these problems, the soybean extract with targeted Lunasin (ET-Lun) was made. The aim of this study was to investigate anti-cancer properties of ET-Lun in breast cancer models in vivo. Methods: Effect of ET-Lun was evaluated in 7,12-Dimetilbenzla]antrasen (DMBA) induced breast cancer rat model. Tumor Mass, volume, and number were measured. The expression of HER2 and EGFR from each treatment group in DMBA-induced rat was evaluated using immunohistochemistry. Results: The results shown that ET-Lun could reduced tumor volume $(p=0,021)$. ET-Lun decreased EGFR expression compared to negative control DMBA $(p=0,012)$ Conclusions: These results indicated that the ET-Lun has anti-breast cancer activity in vivo. Key words: In-vivo, Soybean, Breast cancer, HER2, EGFR.
\end{abstract}

\section{INTRODUCTION}

Breast cancer $(\mathrm{BC})$ is the most common malignancy occurred in women worldwide. ${ }^{1}$ In 2018 , Globocan data shown that the BC's prevalence was $11.6 \%{ }^{2}$ Breast cancer is also one of the most frequent cancers in Indonesia. ${ }^{3}$ According to the Riskesdas in 2018, breast cancer prevalent was increased from $1.4 \%$ in 2013 to $1.8 \%$ in $2018 .{ }^{4}$

Cancer therapy is still developing, one way is by natural compound exploration as sources of therapy to reduce side effects which may cause due to undesirable outcomes of chemotherapy. One of the medicinal plants that has anti-cancer activity has and being developed as an anticancer drug is soybeans (Glycine max (L.) Merr.). Consumption of soy products has been known to decrease mortality and incidence of breast cancer ${ }^{5}$, prostate cancer ${ }^{6}$, colon cancer ${ }^{7}$, and lung cancer ${ }^{8,9}$. The active compounds in soybeans were isoflavonoids (genistein, daidzein and glycitein), Bowman-Birk protease inhibitor, Kunitz trypsin inhibitor, sitosterol, saponin, lectins, and lunasin. ${ }^{9-10}$ Isoflavones were compound of flavonoid in soybeans has known as a strong antioxidant. Soybean has many advantages to health may be obtained from isoflavonoid. While many research has been extended to understand the anti-cancer potential of isoflavonoid, not every anti-cancer effect related to soybean consumption was from isoflavonoids. ${ }^{9}$ Recent studies shown that a significant anti-cancer compound in soybean was a bioactive peptide : lunasin. $.^{10},{ }^{11}$

Lunasin is a peptide, consist of 44 amino acids, ${ }^{12}$ which have anti-cancer, ${ }^{9,13}$ antioxidant and anti-inflammatory activity $^{14}$. Galves et al. ${ }^{15}$ demonstrated that lunasin can inhibit the mitosis of MCF-7 cancer cells, murine hepatoma (Hepa 1c1c7), and embryonic fibroblast murine cells (C3H 10T1/2), resulted cell death due to binding chromatin in the kinetochore area in the centromere and blocking the microtubule attachment. Lunasin can also increase apoptosis by inducing PTEN and demonstrated to inhibit caspase-3 in vitro and in vivo. ${ }^{16}$ Previously, lunasin also found to inhibit metastasis by suppressing cellular migration, invasion, and expression of matrix metalloproteinases (MMP)-2 and MMP-9. ${ }^{17}$

However, commercial price of Lunasin was very expensive due to the high cost of lunasin synthesis and the lack of methods to obtain the pure lunasin weight from plant sources, involving time-consuming analytical instruments. ${ }^{18-19}$ The concentration of Lunasin may be influenced by cultivar, environmental factors, in particular temperature and conditions during processing. ${ }^{20}$ To overcome such limitations, the soybean extract with targeted Lunasin (ET-Lun) was made. This extraction method was obtained from several combinations of research that conducted by Vuyyuri, et $\mathrm{al}^{9}$, and Serra, et $\mathrm{al}^{19}$. ET-Lun was lunasin that extracted from soybean seed, which that has been undergoing fat removal, followed by PBS solvent under a $\mathrm{pH}$ of 7.4. The lunasin content in the extract was $0.86 \mathrm{mg} / \mathrm{g}$ extract of soybean. ${ }^{21}$

Several studies related to ET-Lun activity, including the potential of ET-Lun to reduced COX-2 expression in a dose of $150 \mathrm{mg} / \mathrm{kg} \mathrm{BW}$ and $200 \mathrm{mg} /$ $\mathrm{kg}$ BW of mice $(\mathrm{p}<0.05)$. ET-Lun were also shown to decrease iNOS expression in a dose of $150 \mathrm{mg} / \mathrm{kg}$ BW of mice. ${ }^{22}$ Moreover, ET-Lun can inhibit Goblet cell counts and micro blood density, ${ }^{23}$ inhibit colon cancer by increased apoptosis in a dose of $150 \mathrm{mg} / \mathrm{kg}$ BW in mice, and reduced dysplasia at a dose of 200 $\mathrm{mg} / \mathrm{kg} \mathrm{BW}$ mice. $^{24}$.

The purpose of this study was to analyze the antibreast cancer activity of ET-Lun in vivo assay. In vivo assay was evaluated the expression of HER2, and EGFR of cancer mammae from the treatment group in DMBA-induced rat by immunohistochemistry. 


\section{METHODS}

\section{Plant material collection, identification and extraction}

Soybean seeds (Glycine max (L.) Merr) of Grobogan variety were purchased and identified from Indonesian Legumens and Tubers Crops Research Institude, (Balitkabi) Malang, East Java. The first extraction process was oil removal of soybean seed by pressing the seeds at 100 $150 \mathrm{~atm}$ for 30 minutes at a temperature of $120^{\circ} \mathrm{F}\left(48.89^{\circ} \mathrm{C}\right)$. The process was followed by a blending process to produce a powder. Soybean powder was macerated in Phosphate Buffered Saline (PBS) solvent at $\mathrm{pH} 7.4$ by volume as much as 5 times of weight of the powder for 60 minutes, followed by filtration using Whatman ${ }^{\mathrm{TM}} 54$. The filtrate was then evaporated using a vacuum rotary evaporator until thick extract was obtained.

\section{Preliminary phytochemical screening}

Preliminary phytochemical screening of ET-Lun was performed on various phytoconstituents such as alkaloids, saponins, tannins, phenolics, flavonoids, triterpenoids, steroids and glycosides, using various reagents. ${ }^{25}$

\section{Quantitative estimation of phytochemicals}

Extract's Phytochemical compounds were analyzed using several methods as follows; water value and ash value determined by Thermal Volumetric Analysis (aufhauser) and Gravimetric analysis, the microbial contaminations and were evaluated using direct inoculation, and heavy metal contaminant was examined using Atomic Absorption Spectrophotometer (AAS)

\section{Ethics and Study Design}

Female Sprague Dawley (SD) rat aged 6 weeks, divided into 5 groups of four animals in each. The groups were normal control (NOR), rats induced by 7,12-Dimethylbenz[a]anthracene (DMBA) that received corn oil as vehicle as negative control. Rats that induced by DMBA were divided into several treatments such as Tamoxifen (TAM), Lunasin (ETLun), and combination of ET-Lun and tamoxifen (Adjuvant group). This experiment has been approved by the Ethics Commission of the Faculty of Medicine, the University of Indonesia (the number certificate was KET-647 / UN2.F1 / ETIK/ PPM.00.02 / 2019

\section{Animal Experimental}

All rats in negative control groups were firstly induced by DMBA that has been dissolved in $2 \mathrm{mg} / \mathrm{ml}$ of corn oil. The DMBA induction was given intra-gastric at a dose of $20 \mathrm{mg} / \mathrm{kg} \mathrm{BW}$, carried out 11 times, twice a week. ${ }^{26}$ Treatment was given to rats with a tumor volume of $1-2 \mathrm{~cm}^{3}$. The ET-Lun group was given ET-Lun at doses $500 \mathrm{mg} / \mathrm{kg} \mathrm{BW,} \mathrm{TAM} \mathrm{was}$ treated with Tamoxifen $10 \mathrm{mg} / \mathrm{kg}$ BW, and adjuvant group was treated with combination ET-Lun and Tamoxifen. Treatment was conducted in 8 weeks. For negative controls, tumor growth in rats was observed for 8 weeks. After following treatment, rats were terminated and the tumor tissue was removed for analysis. Tumor tissue was processed and embedded in paraffin blocks for Immunohistochemical (IHC) testing.

\section{Immunohistochemistry of HER2 and EGFR}

The IHC stain were performed according to the IHC-Paraffin Protocol from Abcam ${ }^{\oplus}$. Assessment of HER2, and EGFR expression was performed using weighted histoscore/ $\mathrm{H}$-Score, which was based on the percentage of stained cells and the intensity of the streaks. The intensity measurement was given a score of $0-3(0=$ none; $1=$ weak; $2=$ moderate; and $3=$ strong). Cell calculations were performed using ImageJ and Image Profiler software, using a histoscore (H-score). The $\mathrm{H}$-score was calculated by multiplying the percentage value of the intensity score. HER2 and EGFR H-Score ${ }^{27,28}=1 \times$ (cell membrane and cytoplasm of tumor cells that stained with weak intensity, $1+)+2 \mathrm{x}$ (cell membrane and cytoplasm of tumor cells were stained with moderate intensity, $2+)+3 \mathrm{x}$ (cell membrane and cytoplasm of tumor cells that stained with with strong intensity, $3+$ ).

\section{RESULTS}

\section{Plant material collection, identification and extraction}

Soybean plant certification was issued by the Indonesian Legumens and Tubers Crops Research Institute, (Balitkabi) Malang, East Java. The variety of soybean seed was Grobogan. (Certificate number is 0310/009. KD. Gro. BS. Kp. 19/08.19-LA).

\section{Physicochemical evaluation}

The standardization of the extract obtained was a water value of $29.82 \%$, ash value of $2.75 \%$ and the percentage of extraction yield was $12.34 \%$, heavy metals; lead $(\mathrm{Pb})$ was $1,05 \mathrm{ppm}$ and cadmium $(\mathrm{Cd})$ was negative. Phytochemical screening found that soybean extracts contained flavonoids, alkaloids, saponins, triterpenoids, and glycosides.

\section{Effect on mammary tumors}

During treatment, tumor diameter and volume were evaluated once a week. The results of tumor volume for 8 weeks of treatment shown that treatment with tamoxifen, ET-Lun, and a combination of ET-Lun and tamoxifen/ adjuvant group, could reduce tumor volume when compared to negative controls (DMBA). The reduction in tumor volume was shown by the adjuvant group (Figure 1). There were differences in the tumor volume of the DMBA group and the ET-Lun and Adjuvant group starting at week 3 to 8 of treatment $(\mathrm{p}<0.05)$. At week 3 , tumor volume of ET-Lun and Adjuvan group were different compared to the negative control group, while but tumor volume of the tamoxifen group did not differ with the negative control group $(p=0.149)$. The tumor volume in the tamoxifen group was different from the DMBA group at week 4 to week 7 ( $p$ <0.05). At week 8 , the tumor volume in the tamoxifen group did not differ from the tumor volume in the DMBA group, whereas the tumor volume in the adjuvant group and the group given ET-Lun shown differences in the DMBA group.

The results of tumor weight $(\mathrm{g} / \mathrm{kg} \mathrm{BW}$ ) after treatment, the group given the ET-Lun, tamoxifen, and the adjuvant group, could reduce tumor weight when compared to negative controls DMBA (Figure 2A). There was no difference in the weight of the DMBA tumor group with the tamoxifen, ET-Lun, and Adjuvant groups ( $\mathrm{p}>0.05$ ). The tumor volume in the tamoxifen group, the ET-Lun group, and the adjuvant group was shown decreased when compared to DMBA negative control group (Figure 2B). Statistical analysis has shown that tumor volume in the DMBA group were differed from the tumor volume in the ET-Lun group $(\mathrm{p}=0.021)$, while no difference in tumor volume of tamoxifen and adjuvant groups $(\mathrm{p}>0.05)$.

\section{Immunohistochemistry analysis for EGFR and HER2}

The expression of EGFR (Figure 3A) showed a significant difference between the negative control DMBA and the group given ET-Lun ( $\mathrm{p}=0,012)$ and adjuvant $(\mathrm{p}=0,021)$. The results of microscopic observation of EGFR expression also showed that the ET-Lun and adjuvant group was able to reduce EGFR expression compared to the DMBA group (Figure 4). EGFR expression is indicated by the presence of brownstained cells (red arrow) on the cell membrane and cytoplasm. HER2 expression is indicated by the presence of brown-stained cells (red arrow) on the cell cytoplasm (Figure 5). In the DMBA group, almost all cell membranes were brown with moderate to strong intensity covering the membrane and cytoplasm. In contrast, in the ET-Lun group, the presence of brown-stained cells were not as much as in the DMBA group with weak intensity. Some epithelial cells were negative stained (blue), with the nucleus still clearly visible. 


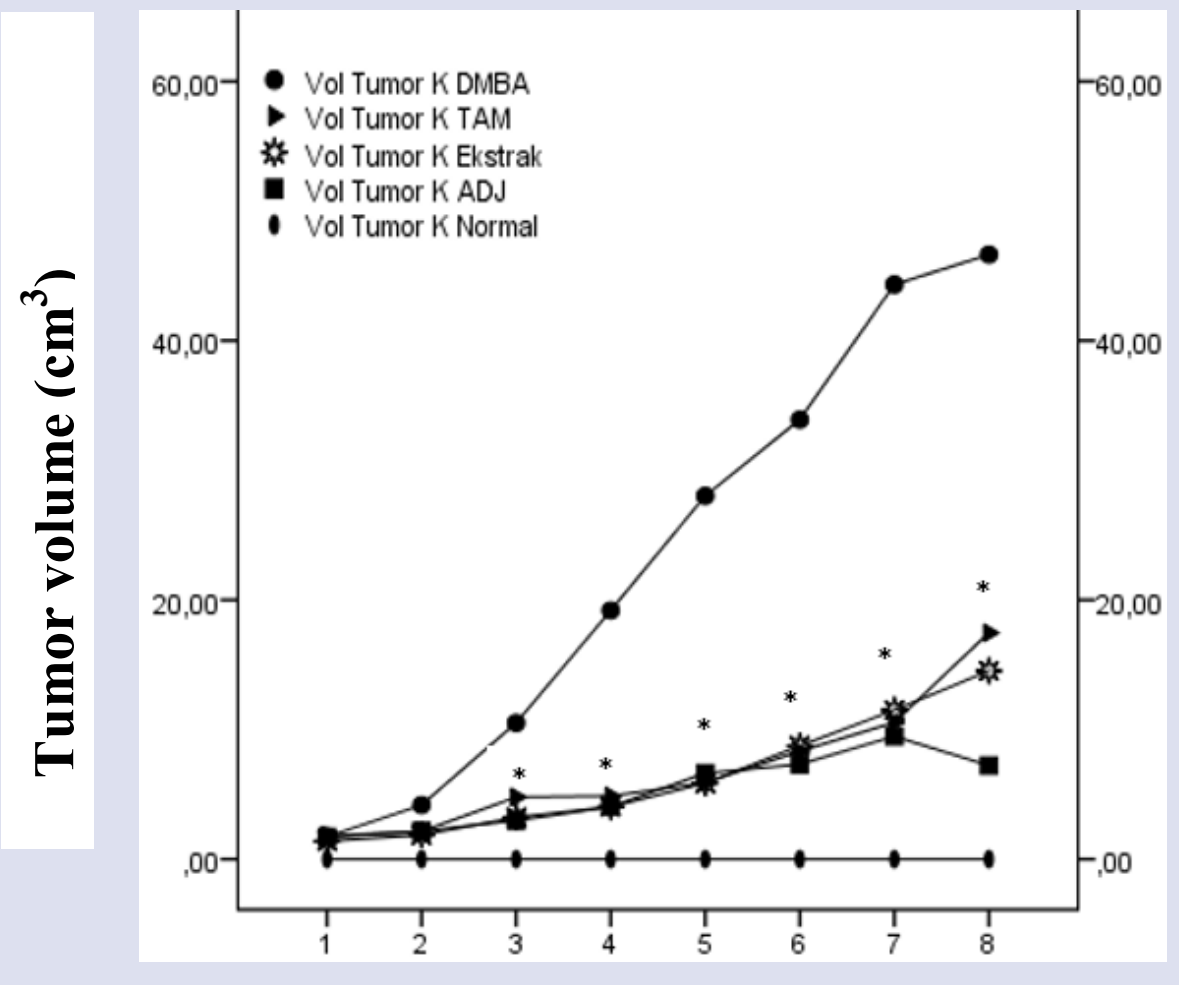

\section{Weeks of treatment}

Figure 1: The tumor volume $(\mathrm{cm} 3)$ for 8 weeks of each group treatment. Normal = normal control treated with corn oil as vehicle. DMBA = negative control treated with DMBA dissolved in corn oil; Tam = positive control treated with tamoxifen $10 \mathrm{mg} / \mathrm{kg} \mathrm{BW.} \mathrm{K}$ extract $=$ treated with ET-Lun $500 \mathrm{mg} / \mathrm{kg}$ BW. Adj $=$ treated with tamoxifen and ET-Lun. ${ }^{*} \mathrm{p}<0,05$ compare negative group (DMBA).

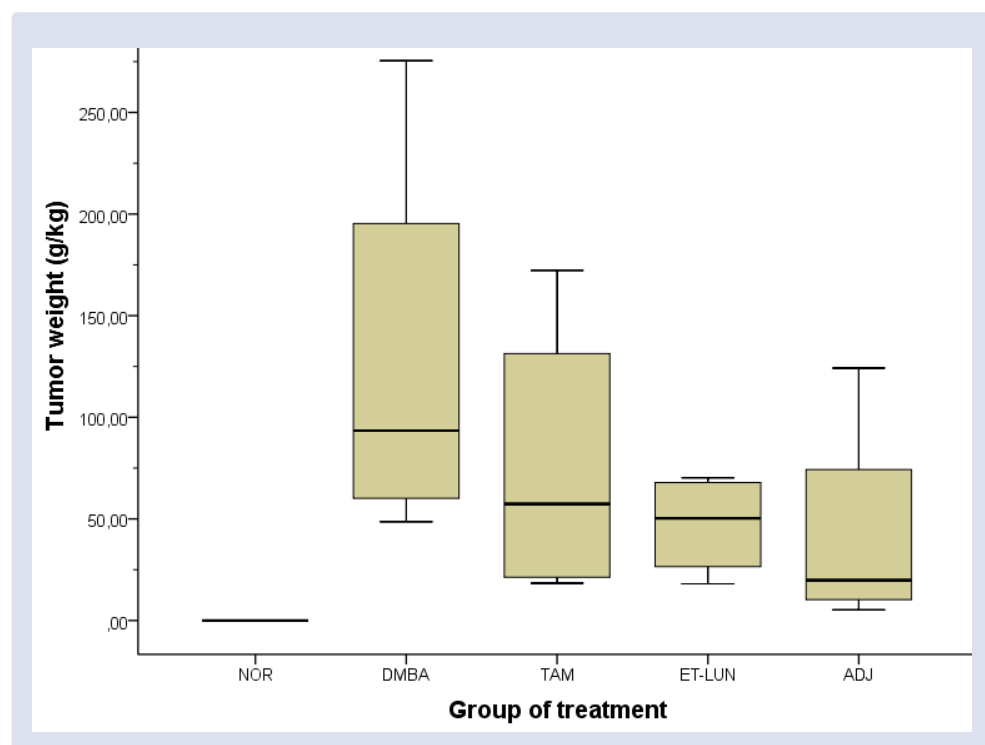

(A)

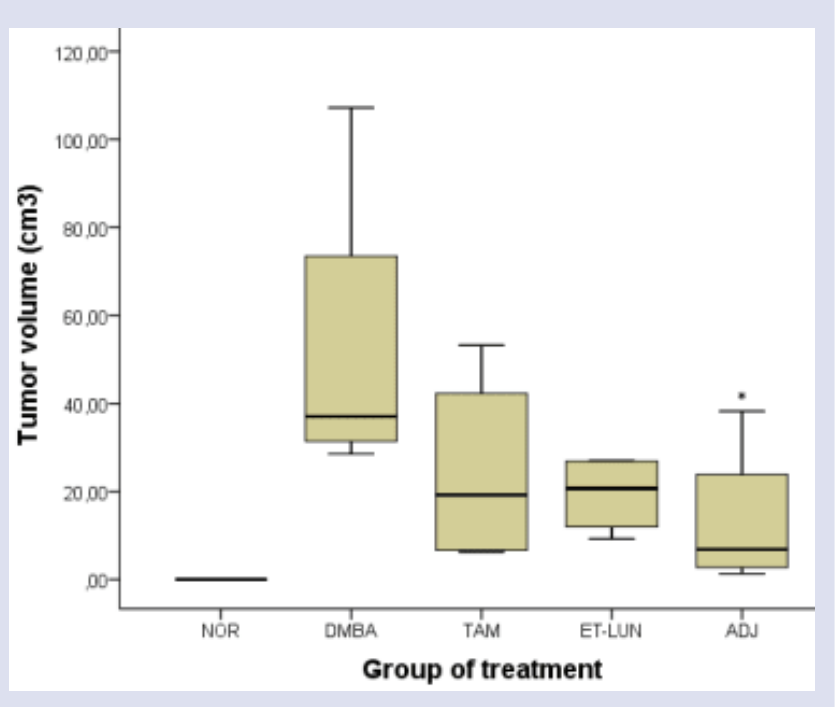

(B)

Figure 2: (A) The weight of tumor after treatment $(\mathrm{g} / \mathrm{kg})$. (B) The volume of tumor after treatment $\left(\mathrm{cm}^{3}\right)$. Nor $=$ normal control treated with corn oil as vehicle. $\mathrm{DMBA}=$ negative control treated with DMBA dissolved in corn oil; Tam = positive control treated with tamoxifen $10 \mathrm{mg} / \mathrm{kg}$ BW. ET-Lun = treated with ET-Lun $500 \mathrm{mg} / \mathrm{kg} \mathrm{BW}$. Adj = treated with tamoxifen and ET-Lun. ${ }^{*} \mathrm{p}<0,05$ compare negative group (DMBA). 


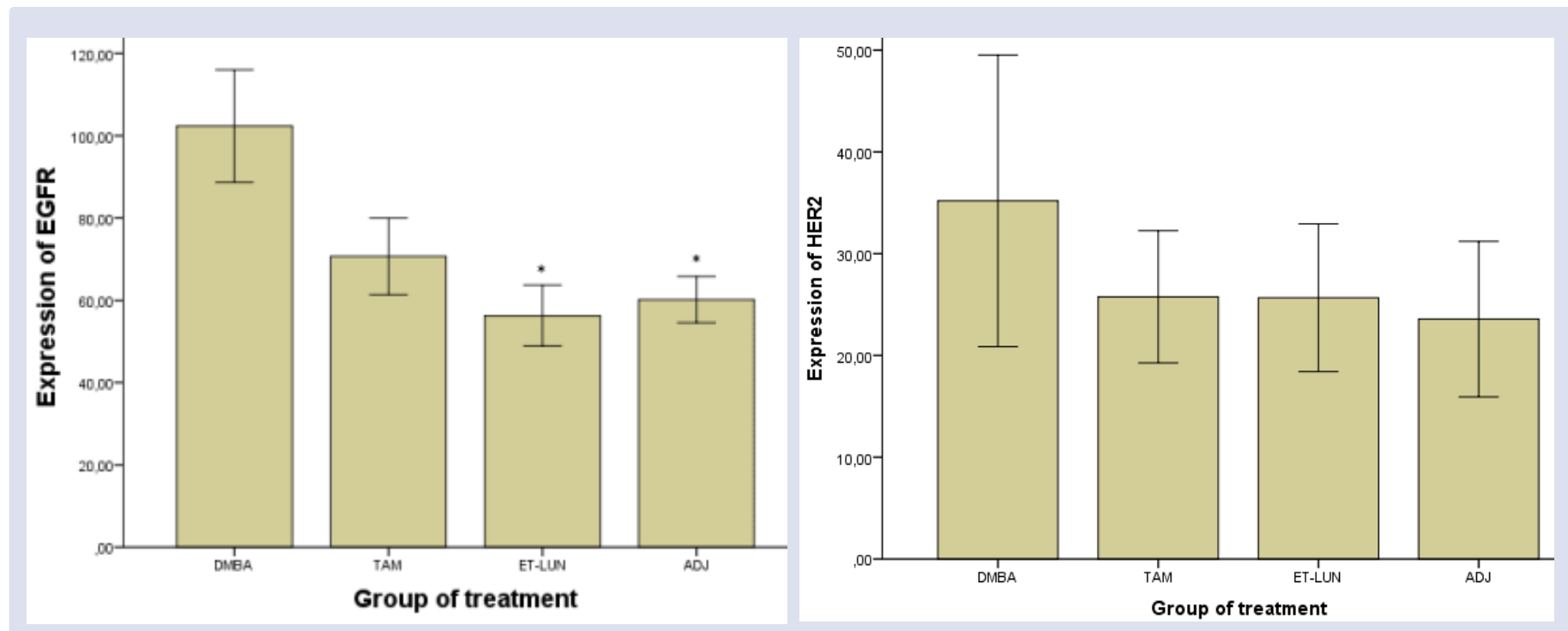

Figure 3: (A) EGFR Expression Score of the treatment group. (B) HER2 Expression Score of the treatment group. DMBA = negative control treated with DMBA dissolved in corn oil; Tam = positive control treated with tamoxifen $10 \mathrm{mg} / \mathrm{kg} \mathrm{BW}$. ET-Lun = treated with ET-Lun $500 \mathrm{mg} / \mathrm{kg} \mathrm{BW.} \mathrm{Adj=} \mathrm{treated} \mathrm{with} \mathrm{tamoxifen}$ and ET-Lun. Data are presented as means \pm SEM $(n=4) .{ }^{* *} p<0,05$ compare DMBA.
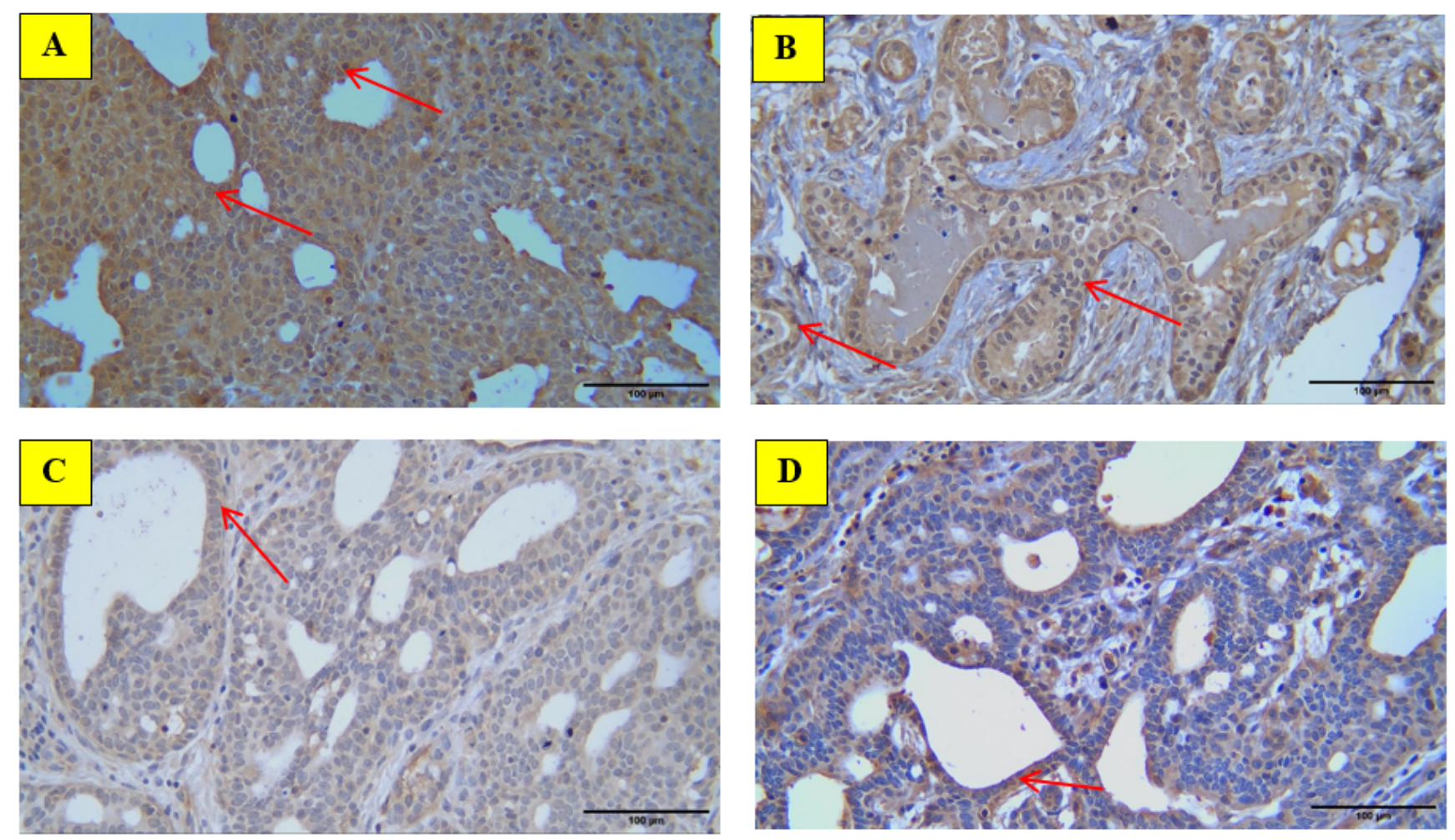

Figure 4: EGFR expression from breast cancer tissue with immunohistochemical staining in the treatment group (400X). (A) DMBA group, (B) Tamoxifen group, (C) ET-Lun, and (D) Adjuvan group.The red arrow indicates the expression of EGFR in membrane and cytoplasm of tumor cells. 

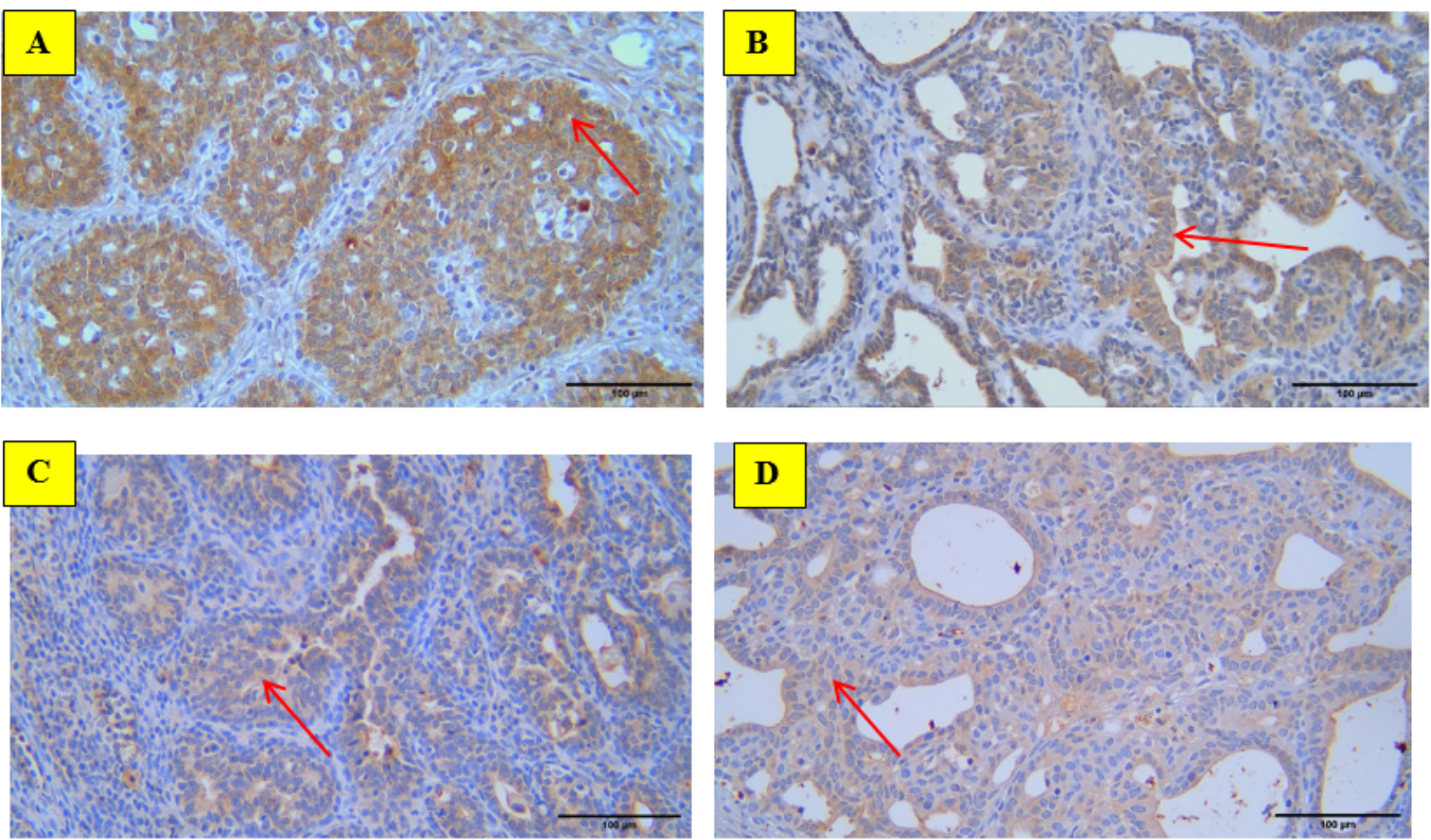

Figure 5: HER2 expression from breast cancer tissue with immunohistochemical staining in the treatment group (400x). (A) DMBA group, (B) Tamoxifen group, (C) ET-Lun, and (D) Adjuvan group. The red arrow indicates the expression of HER2 in cytoplasm of tumor cells.

\section{DISCUSSION}

Authentication and standardization are prerequisite steps while considering the source materials for herbal formulation in any system of medicine. The standardization of medical plant was necessary to ensure the effectiveness, safety, stability, and quality of phytoconstituents in medicinal plant. ${ }^{29}$ The soybean plant is one of the plants whose their activity is being developed as a medical plant. ${ }^{30}$ In this study, the extraction of soybean seed powder followed the previous research procedure. $^{22,24}$

The variation of natural product composition in extract may have the pharmacological effects synergically, so that the characterization of the extract is needed for quality assurance..$^{29}$ The water value is needed to maintain the extract stability. The results of this study shown that the water value of thick extract was $29,82 \%$. This result was in accordance with the requirements for thick extract content to that $5-30 \%{ }^{31}$, while the ash value was $2,75 \%$. The determination of the ash value is an indication of certain medicinal plant species because each plant has specific remains. In additions, the results of microbial contamination and heavy metal contamination are in accordance with the requirements and safety to be used.

Epidermal Growth Factor Receptor (EGFR) overexpression is phenotypes of an aggressive subtype of breast cancer and generally has a poor clinical prognosis. Sprague Dawley rat induced by DMBA, increased expression of ER, PR, EGFR, IGF1R, and activation of MAPK, JNK, and Akt signals, resulted in the development of carcinoma in breast tissue. ${ }^{32,33}$ In this study there increased of EGFR expression was found in DMBA-induced.

Giving ET-Lun can reduce EGFR expression compared to DMBA negative control. This was also supported by a preliminary in silico test explained that lunasin can bind EGFR (data not shown). The binding of ET-Lun to EGFR resulted in decrease of EGFR expression and affects the signal propagations which are responsible for cell growth and apoptosis.

On the other hand, the EGFR expression of the tamoxifen group was not significantly different to the DMBA control group. Tamoxifen is a selective estrogen receptor modulator (SERM), suppress breast cancer growth by acting as an ER antagonist, by binding to the ER and inducing conformational changes that support the recruitment of corepressor proteins nuclear receptor co-repressor (NcoR) and silencing mediator for retinoids and thyroid receptors (SMRT) through the activity of histone deacetylation that plays a role in transcriptional repression. ${ }^{34}$ In this case, tamoxifen acts only as an antiestrogen, but cannot inhibit the integration of signal transduction growth factors, such as EGFR.

The result of HER2 expression showed no difference between the DMBA group and ET-Lun, and Adjuvant groups. There was no difference in HER2 expression in the negative control group with the normal control group, indicated that DMBA induction in SD rats was not affected HER2 signaling. In this study, SD rats induced by DMBA increased the expression of the EGFR growth factor but did not alter HER2 expression.

\section{CONCLUSIONS}

This study demonstrated that ET-Lun could decrease EGFR expression compared to the negative control (DMBA) and might be used as a candidate for anti-breast cancer.

\section{COMPETING OF INTEREST}

None to declare. 


\section{ACKNOWLEDGEMENTS}

Thank you to Directorate of Research \& Development, Ministry of Research, Technology, and Higher Education Repulic of I ndonesia / National Agency for Research for the funds provided (PTUPT contract number NKB-318/UN2.RST/HKP.05.00/2020)

\section{REFERENCES}

1. Ghoncheh M, Pournamdar Z, Salehiniya H. Incidence and mortality and epidemiology of breast cancer in the world. Asian Pacific J Cancer Prev. 2016;17(sup3):43-6.

2. Bray F, Ferlay J, Soerjomataram I, Siegel RL, Torre LA, Jemal A. Global cancer statistics 2018: GLOBOCAN estimates of incidence and mortality worldwide for 36 cancers in 185 countries. Ca Cancer J Clin. 2018;68:394-424.

3. Dewi M. Distributation of Cancer in Indonesia: Basic Health Reseach 2017. Indonesian Journal of Cancer. 2017;11(1):1-8.

4. The Ministry of Health Repuplic Indonesia. The main report of basic health research 2018. in: Basic Health Research 2018. Jakarta.

5. Messina M. Impact of soy foods on the development of breast cancer and the prognosis of breast cancer patients. Forsch Komplementarmed. 2016;23(2):75-80.

6. Jacobsen BK, Knutsen SF, Fraser GE. Does high soy milk intake reduce prostate cancer incidence. The adventist health study (United States). Cancer Causes Control. 1998;9(6):553-7.

7. Yan L, Spitznagel EL, Bosland MC. Soy consumption and colorectal cancer risk in humans: A meta-analysis. Cancer Epidemiol Biomarkers Prev. 2010;19(1):148-58.

8. Yang $W$, Va $P$, Wong $M$, Zhang $H$, Xiang $Y$. Soy intake is associated with lower lung cancer risk: results from a meta-analysis of epidemiologic studies. Am J Clin Nutr. 2011;(2):1575-83.

9. Vuyyuri SB, Shidal C, Davis KR. Development of the plant-derived peptide lunasin as an anticancer agent. Curr Opin Pharmacol. 2018;41:27-33

10. Dia VP, Mejia EG de. Lunasin induces apoptosis and modifies the expression of genes associated with extracellular matrix and cell adhesion in human metastatic colon cancer cells. Mol Nutr Food Res. 2011;55(4):623-34

11. Wan X, Liu H, Sun Y, Zhang J, Chen X, Chen N. Lunasin: A promising polypeptide for the prevention and treatment of cancer. Oncol Lett. 2017;13(6):3997-4001

12. Liu J, Jia SH, Kirberger M, Chen N. Lunasin as a promising healthbeneficial peptide. Eur Rev Med Pharmacol. 2014;18(14):2070-5.

13. Inaba J, McConnell EJ, Davis KR. Lunasin sensitivity in non-small cell lung cancer cells is linked to suppression of integrin signaling and changes in histone acetylation. Int J Mol Sci. 2014;15(12):23705-24

14. Hernández-Ledesma B, Hsieh CC, de Lumen BO. Antioxidant and anti-inflammatory properties of cancer preventive peptide lunasin in RAW 264.7 macrophages. Biochem Biophys Res Commun. 2009;390(3):803-8

15. Galvez AF, De Lumen BO. A soybean cDNA encoding a chromatinbinding peptide inhibits mitosis of mammalian cells. Nat Biotechnol. 1999;17(5):495-500.

16. Pabona JM, Dave B, Su Y, Montales MT, De Lumen BO, De Mejia $E G$, et al. The soybean peptide lunasin promotes apoptosis of mammary epithelial cells via induction of tumor suppressor PTEN: Similarities and distinct actions from soy isoflavone genistein. Genes Nutr. 2013;8(1):79-90.

17. Jiang $\mathrm{Q}$, Pan Y, Cheng Y, Li H, Liu D, Li H. Lunasin suppresses the migration and invasion of breast cancer cells by inhibiting matrix metalloproteinase-2/ -9 via the FAK/ Akt/ ERK and NF-KB signaling pathways. Oncol Rep. 2016;36(1):253-62.
18. Dia VP, Wang W, Gonzales de Mejia E. Isolation, purification and characterisation of lunasin from defatted soybean flour and in vitro evaluation of its anti-inflammatory activity. Food Chem. 2009;114(1):108-15.

19. Serra A, Gallart-Palau X, See-Toh RSE, Hemu X, Tam JP, Sze SK. Commercial processed soy-based food product contains glycated and glycoxidated lunasin proteoforms. Sci Rep. 2016;6:1-12.

20. Wang W, Dia VP, Vasconez M, de Mejia EG NR. Analysis of soybean protein-derived peptides and the effect of cultivar, environmental conditions, and processing on lunasin concentration in soybean and soy products. J AOAC. 2008;4(2008):936-46.

21. Kusmardi K, Karenina V, Estuningtyas A, Tedjo A. Inhibition of Cox-2 Expression by Lunasin-Rich Soybean Extract on Colorecta Cancer. Int J App Pharm, Vol 11, Special Issue 6, 2019, 116-121.

22. Wijiasih, Kusmardi K, Elya B. The effect of soybean and soybean meal extract on COX-2 and iNOS expression in colon preneoplasia of mice induced by azoxymethane and dextran sodium sulfate. Int J ChemTech Res. 2017;10(1):39-46.

23. Putri AS, Elya B, Kusmardi K. Inhibitory activity of Indonesian soybean in comparison with soybean meal on Goblet cell count and micro vessel density in colitis-associated mouse colon carcinogenesis. Int J PharmTech Res. 2017;10(1):9-18.

24. Amalia AW, Kusmardi K, Elya B, Arsianti A. Inhibition of carcinogenesis by seed and soybean meal extract in colon of mice: Apoptosis and dysplasia. Asian J Pharm Clin Res. 2017;10(4):22-7.

25. Hanani E. Phytochemical Analysis. EGC Publisher oh Medical Book Jakarta. 2016.

26. Wibowo $A E$, Sriningsih $S$, Wuyung $P E$, Ranasasmita R. The Influence of DMBA (7,12-dimethylbenz-[a]anthracene) Regimen in the development of mammae carcinogenesis on Sprague-Dawley female rat. Indones J Cancer Chemoprevention. 2010;1(1):60-66.

27. Avilés-Salas A, Muñiz-Hernández $S$, Maldonado-Martínez HA Chanona-Vilchis JG, Ramírez-Tirado LA, Hernández-Pedro N, et al. Reproducibility of the EGFR immunohistochemistry scores for tumor samples from patients with advanced non-small cell lung cancer. Oncol Lett. 2017;13(2):912-20.

28. Hashmi AA, Naz S, Hashmi SK, Irfan M, Hussain ZF, Khan EY, et al Epidermal growth factor receptor (EGFR) overexpression in triplenegative breast cancer: association with clinicopathologic features and prognostic parameters. Surg Exp Pathol. 2019;2(1):1-7.

29. Bijauliya RK, Alok S, Chanchal K, Kumar M. A Comprehensive Review on Standardization of Herbal Drugs. Int J Pharm Sci Res. 2017:8(9):3663-77.

30. Kurosu, M. Biologically Active Molecules from Soybeans, in Soybean and Health. InTech. 2013.

31. Saifudin A, Rahayu V, Teruna HY. Standardization of Natural product. Graha ilmu, Yogjakarta. 2011.

32. Kumar A, Sunita P, Jha S, Pattanayak SP. 7,8-Dihydroxycoumarin exerts antitumor potential on DMBA-induced mammary carcinogenesis by inhibiting ERa, PR, EGFR, and IGF1R: involvement of MAPK1/2-JNK1/2-Akt pathway. J Physiol Biochem 2018;74(2):223-34

33. Benakanakere I, Besch-Williford C, Ellersieck MR, Hyder SM Regression of progestin-accelerated 7,12-dimethylbenz[a] anthracene-induced mammary tumors in Sprague-Dawley rats by p53 reactivation and induction of massive apoptosis: A pilot study. Endocr Relat Cancer. 2009;16(1):85-98

34. Martinkovich S, Shah D, Planey SL, Arnott JA. Selective estrogen receptor modulators: Tissue specificity and clinical utility. Clin Interv Aging. 2014;9:1437-52. 


\section{GRAPHICAL ABSTRACT}

\section{In Vivo Antimammary Tumor Effects of Soybean Extract with Targeted Lunasin (ET-Lun)}

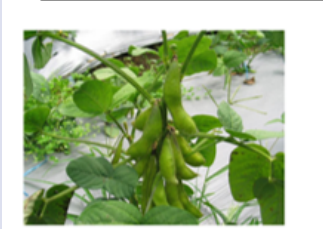

Soybean seeds (Glycine max (L.) Merr) of Grobogan variety from Balitkabi Malang, East Java, Indonesia

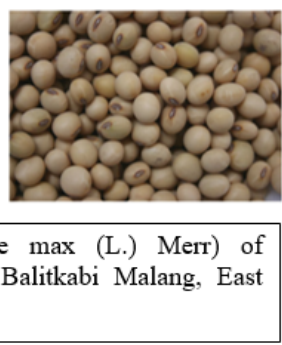

RESULTS:

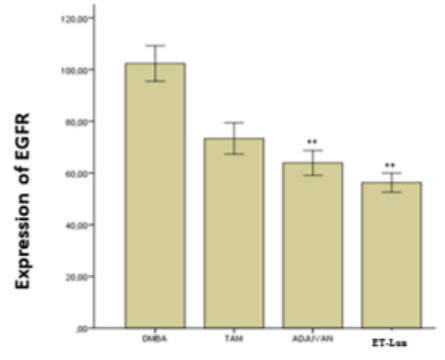

Group of treatment

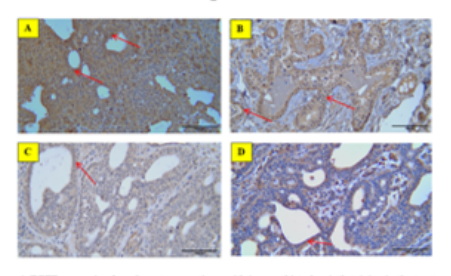

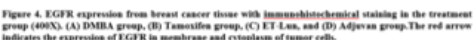

\section{The Concentration of Lunasin was $0,907 \mathrm{mg} / \mathrm{g}$ ET-Lun}

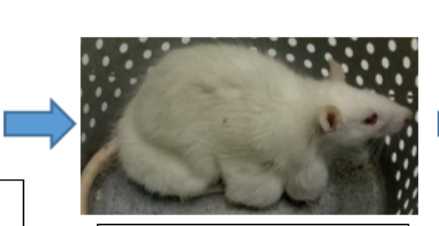

DMBA induced breast cancer rats
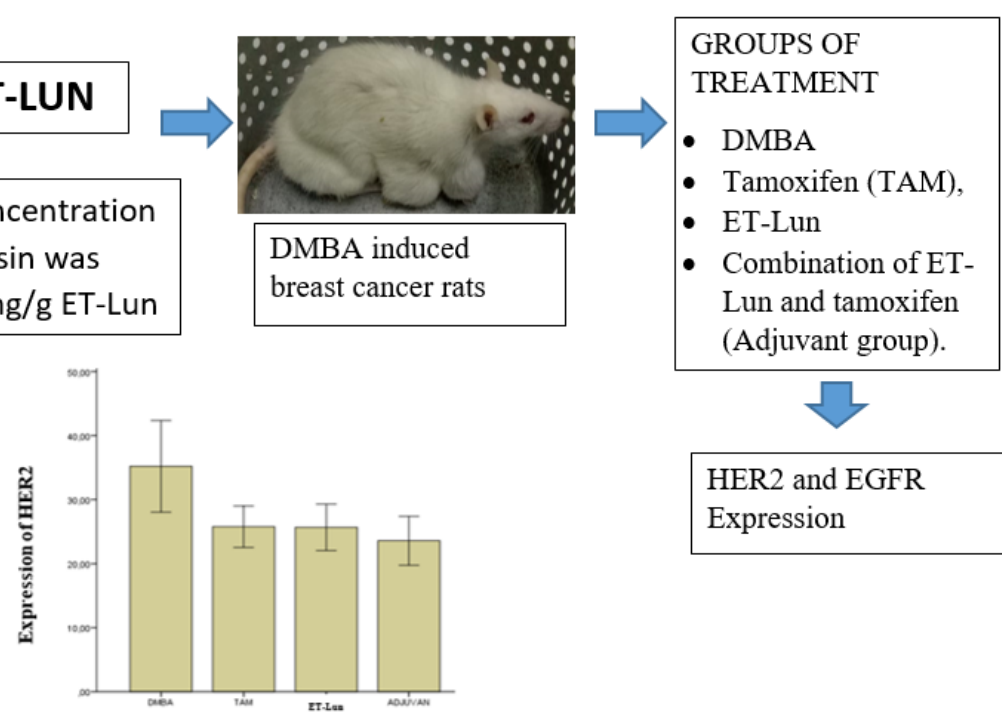

Group of treatment

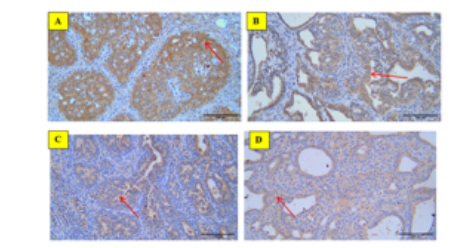

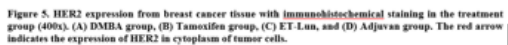

\section{ABOUT AUTHORS}
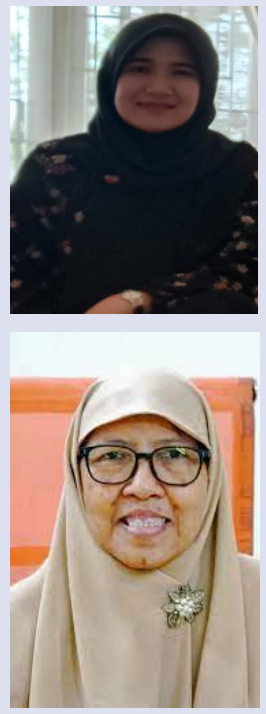

Numlil Khaira Rusdi. Lecturer in the Department of Pharmacy, University of Muhammadiyah Prof. Dr. HAMKA Jakarta. Focuses on Pharmacology and Community Pharmacy, and Doctoral student at Biomedical Sciences, Faculty of Medicine, Universitas Indonesia. She is currently conducting research on anti-breast cancer in medical plants.

Berna Elya, is Professor at the Faculty of Pharmacy, Universitas Indonesia. She is Head of Laboratory of Phy-tochemistry and Pharmacognosy. Has expertise in the area of Pharmacognosy and Phytochemistry of Natural Products, working mainly in: Natural Product Isolation and Bioassay. 


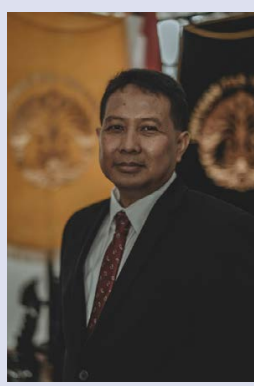

Andon Hestiantoro is a Professor in obstetrics and gynecology, and works as consultant in reproductive endocrinology and infertility. He achieved his MD and PhD degrees from University of Indonesia, Jakarta, and obtained his MPH degree from University of Gajah Mada, Yogyakarta. He is the head of Human Reproduction, Infertility, and Family Planning Cluster, Indonesia Medical and Research Center, Universitas Indonesia. He conducts research activities at the Yasmin Fertility Clinic, Cipto Mangunkusumo Hospital, Jakarta, Indonesia. He is interested in research in female endocrinology.

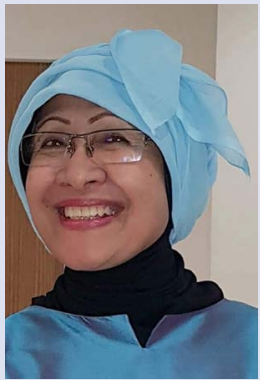

Erni H. Purwaningsih is a Professor in Medical Pharmacy, Faculty of Medicine Universitas Indonesia, and as a vice coordinator of Drug Development Cluster, Institute of Medical Education and Research in Indonesia (IMERI) Universitas Indonesia. She achieved her MD, Magister and Doctor degrees from Faculty of Medicine, Universitas Indonesia. She conducts research activities especially on Herbal Medicine, and as a supervisor for several candidates on Biomedical Magister and/or Doctorate Program Faculty of Medicine, Universitas Indonesia. She is consultant and/or reviewer on Traditional Herbal Medicine that conducted by the Director of Traditional Health Services, the Ministry of Health and for the National Agency of Drug and Food Control of Indonesia.

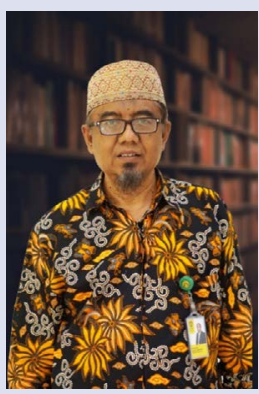

Kusmardi is Associate professor at Anatomic Pathology, Faculty of Medicine, Universitas Indonesia. The major research focus on colorectal and breast cancer, include the potential inhibition of some Indonesian natural medicine on the both carcinogenesis, the indentification of normal tissue vs cancer development using some molecular marker and computational model. He wrote the mouse model for breast cancer book, the mouse model for colorectal adjuvant chemopreventive book, and Lunasin: a soybean polypeptide as chemopreventive adjuvant for colon cancer.

Cite this article: Rusdi NK, Purwaningsih EH, Hestiantoro A, Elya B, Kusmardi K. In Vivo Antimammary Tumor Effects of Soybean Extract with Targeted Lunasin (ET-Lun). Pharmacogn J. 2021;13(5): 1269-1276. 